\title{
US firm's bid to sequence rice genome causes stir in Japan . . .
}

[TOKYO] The Japanese government's Rice Genome Sequencing Project has been thrown into turmoil by the news that Celera Genomics, the US company set up by geneticist J. Craig Venter, plans to sequence the entire rice genome in just six weeks.

Celera plans to create a commercial database of the rice genome. It would be made available to companies for US\$30 million on a five-year contract.

As reported last week in the Japanese biotechnology newsletter Nikkei Biotechnology, Venter plans to sequence the 430megabase rice genome using the 'shotgun' technique. This divides the genome into small, random fragments that are then put together to produce the whole sequence.

Venter confirms that Celera has begun sequencing the rice genome, and says that it is "an important basis for future work on other plant species". He adds: "We are aware of the sensitivity over the work, given the large economic and political interest involved, but we are proceeding in order to create a database available for others."

But Venter's initiative has upset researchers involved in the international rice genome project, a ten-year initiative costing US\$200 million that plans to complete the sequencing by 2008 . The project, led by Japan's Ministry of Agriculture, Forestry and Fisheries (MAFF), had aimed to have sequenced 40 per cent of the genome by 2003 .

Takuji Sasaki, leader of MAFF's Rice Genome Research Program, says they will have to speed up their sequencing work. "Although we have been aware of Celera's interest in the rice genome, we are furious at this news," says Sasaki. He says the current project will adopt a new strategy aimed at creating physical maps of all 12 chromosomes by the end of the year. This will be done by mapping 'expressed sequence tags' in rice onto clones of yeast artificial chromosome, focusing on the 'gene-rich' portion of the sequence.

But he admits that Japanese researchers will be unable to compete with Celera in terms of the speed of sequencing. The US company, which is partly owned by the laboratory equipment manufacturer Perkin-Elmer, owns nearly 300 high-speed automated DNA sequencers. "We have applied for additional funding to buy DNA sequencers, but will have to wait two years for the budget to come through," says Sasaki.

Some researchers are sceptical that Celera can complete the sequencing in six weeks. "Six weeks is an exaggeration - a reliable sequence for the rice genome cannot be

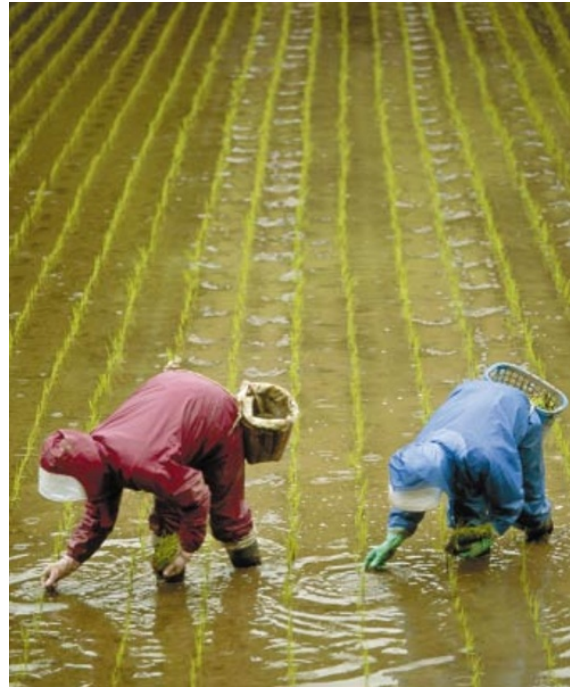

Slow business: Critics say that Japan has not responded to competition in genome research.

obtained by such a fast-track method," says Michio Oishi, director of the Kazusa DNA Research Centre, Japan's first institute dedicated to the sequencing and analysis of DNA.

Oishi predicts that Venter's approach will produce " 80 to 90 per cent of the sequence data", but he notes that the objectives of the two sequencing efforts are very different.

Sasaki says that while the public project aims to provide researchers with complete and reliable sequence data, Venter's effort centres around the aim of "licensing whatever he can achieve".

But he points out that the sequencing will require mapping data if the isolated genomic sequences are to be reassembled in the correct order. Venter says he has "sufficient information to complete the sequencing work", although he adds that "Celera would be happy to partner with groups in Japan to help understand the rice genome".

"Although it would be ideal to collaborate with Celera on this project, there will always be a problem about release of the data," says Sasaki. Like the Human Genome Project, the rice project has agreed on the immediate release of the sequence data; but others would like the option of seeking patent protection on some of the sequence information.

Oishi, one of a group of leading researchers who released a statement last year urging the government to tackle genome research on a national basis, admits that "Japan has been particularly slow at responding to the intensifying competition in genome research".

Answering claims that his initiative would damage the 11-nation international rice genome project, whose members include the United States, the European Union, India and China, Venter argues that the public project is still at a very early stage and has made little progress.

"We have the set-up and the technology to proceed with the sequencing work, and although we do not mean to compete with the public initiative, we can't wait until they get their act together," he says. "Sequencing the genome is just the beginning. We must not forget that post-sequencing work - the analysis of the sequence data - requires far more work."

AsakoSaegusa

\section{... as consortium plans free SNP map of human genome}

[LONDON] Ten of the world's leading pharmaceutical companies, together with Britain's Wellcome Trust, are due to confirm today (15 April) that they will fund a US\$45-million map of the variations in the human genetic code that could be linked to common diseases.

The map will not be patented and will be given free to the world's research community. It will be made available to researchers as it is being constructed, and is expected to be completed within two years.

The project aims to identify up to 300,000 variations in the 3 billion nucleotide base pairs that make up the human genome. These variations are called single-nucleotide polymorphisms, or SNPs; one SNP is estimated to occur roughly every 1,000 bases.

In the long term it is hoped that the map will lead to more effective medication, such as 'personalized' drugs, and to the development of smaller and cheaper drug trials.

In the short term, however, an SNP map is expected to help to reduce the incidence of side effects from existing medicines, and to make the search for genes associated with diseases much faster and cheaper.

For example, by comparing SNP maps of individuals suffering from a disorder such as coronary heart disease with maps of healthy people, researchers hope to identify regions of the human genome where genes associat- 
ed with the disease might be found.

The Wellcome Trust will contribute $\$ 30$ million to the project, and has already funded three pilot studies. The SNP Consortium of pharmaceutical companies will contribute the remaining $\$ 15$ million.

The consortium consists of AstraZeneca, Bayer, Bristol-Myers Squibb, Hoffmann-La

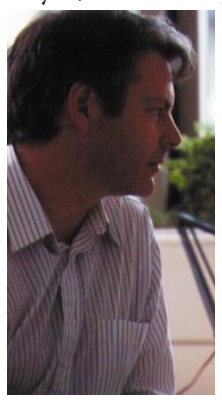

Roche, Glaxo Wellcome, Hoechst Marion Roussel, Novartis, Pfizer, Searle and SmithKline Beecham. The identification and analysis of SNPs will be done at centres involved in the international Human Genome Project.

The US National Institutes of Health has already $\begin{array}{ll}\text { Bentley: maps are } & \text { given } \$ 30 \text { million in grants } \\ \text { 'pre-competitive } & \text { over three years for } a d \text { hoc }\end{array}$ research'? SNP-related projects. The idea that pharmaceutical companies could fund a more comprehensive map emerged from discussions two years ago at the US National Human Genome Research Institute, says Alan Williamson, formerly vice-president for basic research at Merck and a member of the institute's governing council.

Williamson says that pharmaceutical companies were initially approached with the idea of forming a profit-making consortium, which would charge for the use of the map. But those companies that agreed to the idea surprised most observers by insisting that the data should be made available free. The Wellcome Trust's involvement was also conditional on full and free access to the data.

David Bentley, of the Wellcome Trust's Sanger Centre for gene sequencing, says consortium members regard the project as 'precompetitive research', and have agreed not to see any SNP data before they become public.

\section{Glaxo Wellcome is already using map data}

[LONDON] The UK-based drugs company Glaxo Wellcome which says that it has patented the idea of a singlenucleotide polymorphism (SNP) map of the human genome (see page 545) has been attempting for some time to incorporate information about variations in gene sequences into its drug discovery programme.

The company became convinced of the feasibility of mapping the variations in nucleotide base pairs in 1997. Within four months, it had used an SNP map from late- onset Alzheimer's patients to narrow down a possible genetic basis for the disease to just two genes - ApoC1 and $A p o E$.

Over the past two years, the company has launched studies of patients with asthma and coronary heart disease, disorders whose genetic basis is less well known. In addition, it asks patients on clinical trials for many of its drugs for permission to include their genetic profiles in a future SNP database.

According to Allen Roses, a vice-president of Glaxo Wellcome and worldwide director of genetics, a more complete SNP map could establish a genetic basis for handling side effects of drugs.

Roses says doctors are reluctant to prescribe an anticonvulsant drug, Lamictal, because five per cent of patients develop a potentially fatal skin rash as a side effect. If a genetic basis for such side effects were found, patients could be screened, and the drug given to the majority not predisposed to developing the rash.
But the consortium's members will receive an additional benefit. By helping to ensure that SNP data are freely available, the larger pharmaceutical companies will not be restricted to the many proprietary SNP databases already being developed by smaller genomics companies. Indeed, these companies are absent from the SNP Consortium, which is made up exclusively of established pharmaceutical companies.

Celera Genomics near Washington DC is compiling a proprietary SNP database in parallel with its efforts to sequence the human genome. Its president, J. Craig Venter, says he welcomes the new SNP consortium.

Venter says he considers it to be more of a "public education programme" in SNPs than a threat to companies such as Celera. He adds that he expects considerable demand for Celera's product, which, he says, is the subject of a possible patent application.

Two pharmaceutical companies outside the consortium - Amgen and Pharmacia UpJohn - have already signed up, says Venter, adding that Celera expects to obtain between 20 and 30 million SNPs within the next 18 months, two orders of magnitude more than the SNP Consortium. Celera's database, he envisages, could also be augmented by data from the SNP Consortium.

But Allen Roses, a vice-president of Glaxo Wellcome and worldwide director of genetics, says 200,000 SNPs are enough for most practical purposes, such as clinical trials.

Roses claims that it is too late to patent an SNP map, as the concept is no longer novel. He says that the basic idea has already been patented by Glaxo Wellcome (see above) following a mapping exercise to find genes associated with Alzheimer's disease.

Furthermore, says Roses, companies marketing SNP databases will not be allowed to sell data obtained from the SNP Consortium back to a consortium member. EhsanMasood

\section{French research would benefit from less paperwork, says report}

[PARIS] France should create a structure to coordinate administrative tasks across its research agencies. This is one of the main conclusions of a report on research bureaucracy, commissioned by the ministry of national education, research and technology and released last week.

The report was prepared by Marc Goujon, a researcher at the Centre National de la Recherche Scientifique (CNRS), and Gérard Chastagnaret, head of the Mediterranean Centre for the Sciences of Man, following extensive consultation in the research community.

Hardly surprisingly, the report confirms that researchers spend increasing amounts of time on administrative tasks, for which they are often poorly qualified. At the same time, the 26,000-strong CNRS, which is often perceived as a bastion of democracy, emerges from the report as relatively efficient.

It dedicates just 8.5 per cent of its staff and 7.6 per cent of its budget to administration - a share that would be the envy of many private companies. In contrast, the computing agency INRIA allocates 35 per cent of its staff and 18 per cent of its budget to management.

The report deplores the way scientists often have to deal with five layers of regulations: Europe, the state, the regions, the agencies to which they belong and the universities where their laboratories are based. It upholds the CNRS's decentralization of administration away from Paris, through the creation of a series of regional delegations, as a model for other agencies to simplify procedures.
The report criticizes the fact that each agency tends to operate in isolation from the others, resulting in incoherence and duplication. Each agency has developed its own expensive solutions to address the Millennium Bug computer problem, for example, and each has its own scientific press. An interagency structure could centralize many tasks such as training and management of laboratory budgets, says the report.

Claude Allègre, the science minister and an Internet enthusiast, is likely to be pleased by one of the report's recommendations: that the paper mountain associated with administering research should be slashed by implementing security systems to give emails the same legal status as signed paper documents.
Declan Butler 